\title{
What could explain the lower COVID-19 burden in Africa despite considerable circulation of the SARS-CoV-2 virus?
}

\author{
Authors: \\ Richard G. Wamai ${ }^{*}$, Jason L. Hirsch ${ }^{\mathrm{a}}$, Wim Van Damme ${ }^{\mathrm{b}}$, David Alnwick ${ }^{\mathrm{c}}$, Robert C. Bailey ${ }^{\mathrm{d}}$, \\ Stephen Hodgins ${ }^{\mathrm{e}}$, Uzma Alam ${ }^{\mathrm{f}}$, Mamka Anyona ${ }^{\mathrm{g}}$ \\ ${ }^{a}$ Department of Cultures, Societies and Global Studies, Northeastern University, Boston, MA, U.S., \\ Postal Address: 201 Renaissance Park, 360 Huntington Ave, Boston, MA 02115. \\ Email Addresses: * r.wamai@northeastern.edu; Hirsch.ja@northeastern.edu \\ ${ }^{b}$ Department of Public Health, Institute of Tropical Medicine, Antwerp, Belgium., \\ Postal Address: Nationalestraat 155, B-2000 Antwerpen, Belgium. \\ Email Address: WVDamme@itg.be
}

${ }^{c}$ DUNDEX (Deployable U.N.-experienced Development Experts), Belturbet, Ireland.

Postal Address: 39 Riverrun, Belturbet, H14, FX68, Ireland.

Email Address: dalnwick@gmail.com

${ }^{e}$ School of Public Health, University of Illinois at Chicago, Chicago, IL, U.S.

Postal Address: 1603 W Taylor St, Chicago, IL 60612

Email Address: rcbailey@uic.edu

${ }^{f}$ School of Public Health, University of Alberta, Edmonton, AB, Canada.

Postal Address: 11405 - 87 Ave, Edmonton AB T6G 1C9 Canada.

Email Address: shodgins@ualberta.ca

${ }^{g}$ Researcher Africa Institute for Health Policy Foundation, Nairobi, Kenya.

Postal Address: PO BOX 5726600200 . Nairobi, Kenya.

Email Address: u.alam@aasciences.africa

${ }^{h}$ Harvard T.H. Chan School of Public Health, Boston, MA, U.S.

Postal Address: 665 Huntington Ave, Boston, MA 02115

Email Address: mamka.anyona@gmail.com

*Correspondence: Richard G. Wamai, r.wamai@northeastern.edu, 201 Renaissance Park, 360

Huntington Ave, Boston, MA 02115, Primary Kenya Phone: (+254) 711.877.697; Primary U.S. Phone:

(+1)781.539.9399; Secondary U.S. Phone: (+1)617.373.4130. U.S. Fax (+1)617.373.2625. 


\begin{abstract}
COVID-19 differential spread and impacts across regions is a major focus for researchers and policy makers. Africa has attracted tremendous attention due to predictions of catastrophic impacts that have not yet materialized. Early in the pandemic, the seemingly low African case count was largely attributed to low testing and case reporting. However, there is also reason to consider that many African countries got out ahead of the virus early on. Factors explaining low spread include early government mandated lockdowns, community-wide actions, population distribution, social contacts, and ecology of human habitation. While recent data from seroprevalence studies posit more extensive circulation of the virus, continuing low COVID-19 burden may be explained by the demographic pyramid, prevalence of pre-existing conditions, trained immunity, genetics, and broader sociocultural dynamics. Though all these prongs contribute to the observed profile of COVID-19 in Africa, some provide stronger evidence than others. This review is important to expand what is known about the differential impacts of pandemics enhancing scientific understanding and gearing appropriate public health responses. Also, highlighting potential lessons the world may draw from Africa for global health on assumptions regarding deadly viral pandemics given its long experience with infectious diseases.
\end{abstract}

Keywords: COVID-19 pandemic; Africa; SARS-CoV-2 virus spread; lower COVID-19 disease burden; African populations; demographic pyramid; trained immunity; government measures

\title{
Background
}

Now more than one year since the first confirmed severe acute respiratory syndrome coronavirus 2 (SARS-CoV-2, COVID-19) case in Africa was reported in Egypt on February 14, 2020, approximately 4.7 million infections have been reported continentwide as of May 18, $2021^{1}$. Africa has accounted for just $2.9 \%$ of 164 million lab-confirmed cases ${ }^{2}$ despite containing $12.5 \%$ of the global population ${ }^{3}$. Africa's share of deaths is just $4 \%$ of the 3.4 million reported globally $^{2}$. These numbers significantly defy early predictions of mass COVID-19 catastrophe ${ }^{4-7}$. The doom and gloom predictions were based on what was known about how the disease is transmitted and how socially deprived settings, unsanitary living conditions, and weak health systems common throughout the continent could exacerbate spread and subsequent disease burden $^{6,8,9}$.

Almost a year and a half into the pandemic, mass infection spread, high rates of severe disease, and mortality have not been reported ${ }^{10}$. One important exception is South Africa, which carries a substantial $47 \%$ of the confirmed cases and half of deaths among the 55 countries on the continent ${ }^{1}$. This lends reason to question the differences in reporting between African countries as South Africa makes up only $4.8 \%$ of the 1.2 billion people living in Africa and has conducted $24 \%$ of the 45.9 million tests administered as of May $18,2021^{1}$.

Low testing capacities mean that Africa has conducted the least number of tests of all global regions given population size ${ }^{1,11}$, but has exceeded the Africa Centres for Disease Control and Prevention (Africa CDC) targets of 8,000 tests per million ${ }^{1}$. This should be seriously considered as having contributed to an underestimation of cases ${ }^{12}$. Several seroprevalence studies offer insights on the extent of spread in the continent. A cross-sectional household study in Zambia reported much higher infections than reported via the limited normative testing, which showed only one confirmed case reported for every 92 community infections ${ }^{13}$. Small antibody 
studies among healthcare workers in hospitals have reported up to $36 \%$ prevalence in Kinshasa, $\mathrm{DRC}^{14}, 45.1 \%$ in Ibadan, Nigeria ${ }^{15}$, and $12.3 \%$ in Blantyre, Malawi ${ }^{16}$ during the period of May to June 2020. Studies among blood donors in Kenya and in South Africa from April to June 2020 report anti-SARS-CoV-2 IgG seroprevalence of, respectively, $4.5 \%$ nationally ${ }^{17}$ and $60 \%$ among South African black populations, seven times that of in-country white populations ${ }^{18}$. Two studies reported SARS-CoV-2-IgG positivity of $23.7 \%$ in workers of low socio-economic status in Cape Town, South Africa ${ }^{19}$ and $25.1 \%$ in gold mine workers and administrative staff in Ivory Coast ${ }^{20}$. These studies collected blood samples between April and October 2020, during the first wave of COVID-19 spread throughout the continent, with the second wave largely peaking around December $2020^{21}$. While these studies offer insights, a true picture requires that more and larger antibody studies be conducted in other geographies and populations ${ }^{22}$. Additionally, these data should be interpreted with caution, as none of these tests have been validated in African contexts where it is possible that cross-reactivity with other prevalent viruses, micro-organisms and hypergammaglobulinemia due to malaria exposure may influence on sensitivity and/or specificity of these tests, potentially leading to either an underestimation or overestimation of seroprevalence ${ }^{14,23-27}$.

The integrity of reporting case and death data in Africa has been repeatedly called into question. For instance, in January 2021, The New York Times published an article titled "A Continent Where the Dead Are Not Counted"28. However, while on $34.6 \%$ of countries have complete death registration data in the Civil Registration and Vital Statistics (CRVS) in most African countries, all countries have a system in place $^{29}$, and there is no evidence that COVID-19 mortality data is less accurately reported in Africa than elsewhere. Only Tanzania ceased reporting COVID-19 cases or deaths since May 2020 ${ }^{1}$. The World Mortality Dataset reports undercounting of COVID-19 deaths from many of the 77 countries included in the dataset such as the U.S., U.K., and Russia, with only South Africa, Egypt and Mauritius being the only African countries listed ${ }^{30}$. While there are some reports of excess deaths from the continent ${ }^{30,31}$, these may well be more due to the effects of pandemic prevention measures such as lockdowns ${ }^{32}$ than to COVID-19 itself. Nevertheless, rapid mortality assessments for COVID-19 underway in some countries ${ }^{33-36}$ could reveal a more complete picture.

While various studies have postulated that demographics, early actions such as lockdowns, community factors and possibly population-specific innate immune factors yet undetermined ${ }^{9,12,37}$ have played a role in the apparently lower burden, the data and speculation still leave a paradox ${ }^{38,39}$. Several articles in the popular media ${ }^{40,41}$ postulate several hypotheses but to our knowledge there has not yet been a complete scholarly review. We are beginning to understand that context and history matter a great deal ${ }^{42-44}$. The first modeling of the pandemic for nearly all countries in Africa based on multiple context-specific covariates had predicted more closely what has been observed ${ }^{45}$. Here, a set of hypotheses to explore observations regarding SARS-CoV-2 spread and a comparatively low COVID-19 disease burden in the African region are examined. An analysis of factors underlying spread and burden is important because of the potential for valuable lessons to global public health on assumptions regarding deadly viral pandemics, population and systems-level preparedness, and response.

\section{On SARS-CoV-2 Spread}

In order to understand the full picture of COVID-19 in Africa, we must first examine how spread patterns emerged and what variables could have influenced these patterns. While recent 
data has shown extensive SARS-CoV-2 spread on the continent, this was not always thought to be the case and the extent of spread compared with other global regions is still somewhat debated. Below, we present three main areas of interest regarding viral propagation in an Africaspecific context.

\section{Early Government Measures and Messaging}

Many governments in Africa enacted early response measures to respond to the pandemic $^{46-49}$. Even before there was a single case reported in the continent, the Africa CDC had established the Africa Taskforce for Coronavirus (AFCOR) on February 5, 2020, and on April 22, 2020, the WHO highlighted examples of how Africa was leading the global response. By April 15, 2020, 96\% of the 50 African countries examined had in place at least five 'stringent public health and social measures ${ }^{21}$. Less international connectivity, early border closures and lockdowns to prevent viral importation from international flight arrivals, especially from China ${ }^{8}$, were associated with a lower case load ${ }^{50}$. Modelling studies also found reduced connectivity/travel at regional, national, and international levels as having an important early impact in slowing spread ${ }^{45,51}$

Destructive epidemics are not new phenomena for Africa. The continent is constantly dealing with abundant infectious disease (e.g., malaria, yellow fever, tuberculosis, Ebola, polio $)^{52}$. Due to their familiarity with these epidemics, many governments have developed effective public health programs with messaging aimed at unifying the community and highlighting the need for preventative action among individuals ${ }^{53,54}$; for example the case of response to Ebola in Western Africa ${ }^{55-57}$ and to the HIV/AIDS epidemic in Uganda ${ }^{58}$. A similar unity around public health messaging has emerged around COVID-19 in many countries including outside Africa such as in Vietnam (e.g., "Fighting the epidemic is like fighting against the enemy" $)^{12}$. It is very possible that a baseline individual and community preparedness, awareness and adherence to government public health recommendations on non-pharmaceutical interventions, and readiness to adapt to a new epidemic had significant implications in stunting disease spread in the community.

Recent studies point to cultural adherence to government recommendations as being important for mitigating COVID-19 spread $^{59,60}$. But are Africans, on average, more willing to respect in-country public health guidelines? Several surveys on adherence to masking, distancing and hand hygiene have been conducted in multiple countries, some nationally representative ${ }^{61}$. Studies from Nigeria, Malawi, Ethiopia, Ghana, Kenya, and the DRC showed that although participants had a good knowledge about COVID-19 transmission modes and prevention mechanism, consistent over place and time, there were gaps in the practices that prevent COVID$19^{62-66}$. Studies further determined that individuals' age, sex, educational status, occupation, and income level were associated with COVID-19 related practices ${ }^{62,64,67,68}$. From these studies it can be concluded that awareness and (non)adherence to NPIs does not explain low reported cases.

\section{Population Distribution and Structure of Social Networks}

Population structure and spatial distribution strongly predict the patterns of SARS-CoV-2 transmission in communities ${ }^{69,70}$. Analysis of spatial and temporal clustering of populations show a correlation between density/crowding and viral reproduction number ${ }^{69}$. Africa is the least urbanized global region with $55 \%$ of the continent's population living in rural areas with wide 
variations across countries ${ }^{71,72}$. Modeling shows greater reproduction rates in urban areas ${ }^{45,73}$ and epidemiological data is skewed towards higher cases in urban areas across all countries ${ }^{51,74}$. A similar pattern was observed for Ebola ${ }^{75}$. South Africa, clearly the COVID-19 exception on the continent, is a rapidly urbanizing outlier as only $30 \%$ of its population live in rural areas ${ }^{72}$. Nigeria, on the other hand, models the trends seen in the continent as a whole, with approximately $50 \%$ rural population ${ }^{72}$ and a low COVID-19 burden ${ }^{1}$. Limited research in Africa also shows significantly more intergenerational contacts in rural as compared to urban areas ${ }^{76}$. Researchers posit this distribution, household size, and patterns of age-structured social contacts modify the spread of epidemics ${ }^{45,73,76,77}$. Further, a recent study depicts the effect that the nature of social networks and mobility have on COVID-19 transmission ${ }^{78}$. Communities with increased social capital tend to see worse disease outbreaks overall ${ }^{78,79}$, although this is not always the case $^{80}$. An increased feeling of integration and connection to society is beneficial in terms of social support, but may generally have negative consequences for containing infectious disease $\operatorname{spread}^{77}$.

The limited research done on social contact in Sub-Saharan Africa (SSA) shows that enhancing social distance mitigation strategies, particularly for elderly populations, would result in mortality decreases, but not to the extent that these changes would have in higher income settings, which tend to have increased proportions of elderly cohorts in the population ${ }^{9}$. The small slice of the African population who are older (only 3\% of the African population is $65+)^{3}$ live overwhelmingly at home, often with extended families spanning multiple generations. This alone explains a huge discrepancy in cases as roughly one third to half of deaths in wealthy countries such as the U.S. have resulted from superspreading events in elderly nursing homes and assisted living facilities ${ }^{81,82}$. While multiple family homes generally have more people in a shared space than the typical single-family homes of Western countries, this slightly increased risk of within-household spread is offset by the significantly decreased risk of largescale superspreading events in the community often caused by congregate nursing home settings ${ }^{83}$. Despite an increasing trend of elders being cared for in long term care facilities in Africa $^{84}$, especially in South Africa ${ }^{85}$, this is still far less commonly practiced than in Western countries, Asia ${ }^{86}$ or Latin America ${ }^{87,88}$.

\section{A Largely Outdoor Existence}

Because infected persons transmit the virus through coughing, sneezing, talking, singing and breathing ${ }^{89}$, living environments matter. Further, viability and infectivity is influenced by environmental conditions ${ }^{43,90}$. Studies show that coronavirus transmission, while also possible outdoors $^{91}$, is concentrated in indoor settings where it is estimated to be about 19 times higher ${ }^{92}$. While most likely only minimally contributing to viral spread, built environments requiring ventilation, air-conditioning/heating, wastewater and sewer systems have been shown to carry the virus that may escape through aerosolization ${ }^{93-95}$. These systems are generally in urban areas and are almost entirely lacking in rural Africa where most people live. In contrast, respondents in the U.S. National Human Activity Pattern Survey reported spending over $90 \%$ of time in enclosed environments either in buildings or in their cars ${ }^{93,96}$.

In contrast, in Africa where most people live in rural areas, rural livelihoods dependent on agricultural and pastoralism favor dawn-to-dusk outdoor lifestyles with shelters used mostly for sleeping. Research shows people in rural areas spend far more time outdoors as compared to urban areas ${ }^{97}$. Even in the case for sleeping, these homes are often well ventilated with outside 
air, significantly reducing the chance of viral transmission when compared to tightly enclosed indoor spaces in developed countries. Additionally, higher temperatures and UV light intensity have been shown to predict SARS-COV-2 spread $^{98,99}$, although the evidence is inconsistent ${ }^{100}$. Prolonged, year-round outdoor living with direct exposure to UV light in mostly warmer climates all year in the African tropics could partially explain reduced transmission ${ }^{43}$ perhaps due in part to endogenously produced vitamin D, whose benefit regarding COVID-19 is suggested in some studies including a systematic review and meta-analysis ${ }^{101,102}$, and vitamin D supplements are under several ongoing clinical investigations ${ }^{103}$.

As a final note regarding extent of transmission, even if the SARS-CoV-2 virus is more widespread than reported as seroprevalence data suggest, there still has been much less morbidity and mortality observed. The proposed factors reviewed above provide some insight into how African-specific transmission patterns emerged and evolved over time.

\section{Factors mitigating COVID-19 Burden in Africa}

Even though case and death reporting has certainly been less reliable in Africa, there has been very little evidence of increased overall mortality or widespread COVID-19 disease, with the exceptions of South Africa and northern Africa. We now examine what could possibly explain this "mystery", as several scholars and other commentators have characterized it.

\section{Demographic Pyramid}

It is beyond doubt that the demographic pyramid is significantly related to decreased COVID-19 burden. It is well documented that COVID-19 burden is heavily skewed towards older populations ${ }^{104,105}$, as demonstrated by a study of 17 million COVID-19 cases $^{106}$. Compared to a reference demographic group of 5-17 years, the demographic of 65-74 years is 35 times more likely to become hospitalized from COVID-19 infection and 1100 times more likely to die from the disease with these risks increasing significantly with even higher age groups ${ }^{105,106}$. Africa has the youngest population among global regions with a median age of 19.7 years ${ }^{25,48}$. Conversely, the median ages among the hardest hit countries are much higher: 26.8 years in India $^{107}, 31.4$ years in Brazil ${ }^{108}, 38.5$ years in the U.S. ${ }^{109}$, and 40.5 years in the U.K ${ }^{110}$. Modelling clearly show COVID-19 mortality for Africa tracks this similar age pattern ${ }^{45,51}$. and this is confirmed by actual current mortality data ${ }^{111}$. Our analysis shows that $40 \%$ of the betweencountry variance in mortality is accounted for by age structure (Figure 1) $)^{2,72,112}$. These data provide evidence that despite considerable spread of infection, COVID-19 disease and mortality burden in younger African populations is comparatively absent. However, South Africa shows much higher mortality for a similar age structure to many countries including India and Egypt meaning other factors are also at play. 
Figure 1: Cumulative COVID-19 deaths per million vs. Percentage age $65+/ 15-64$

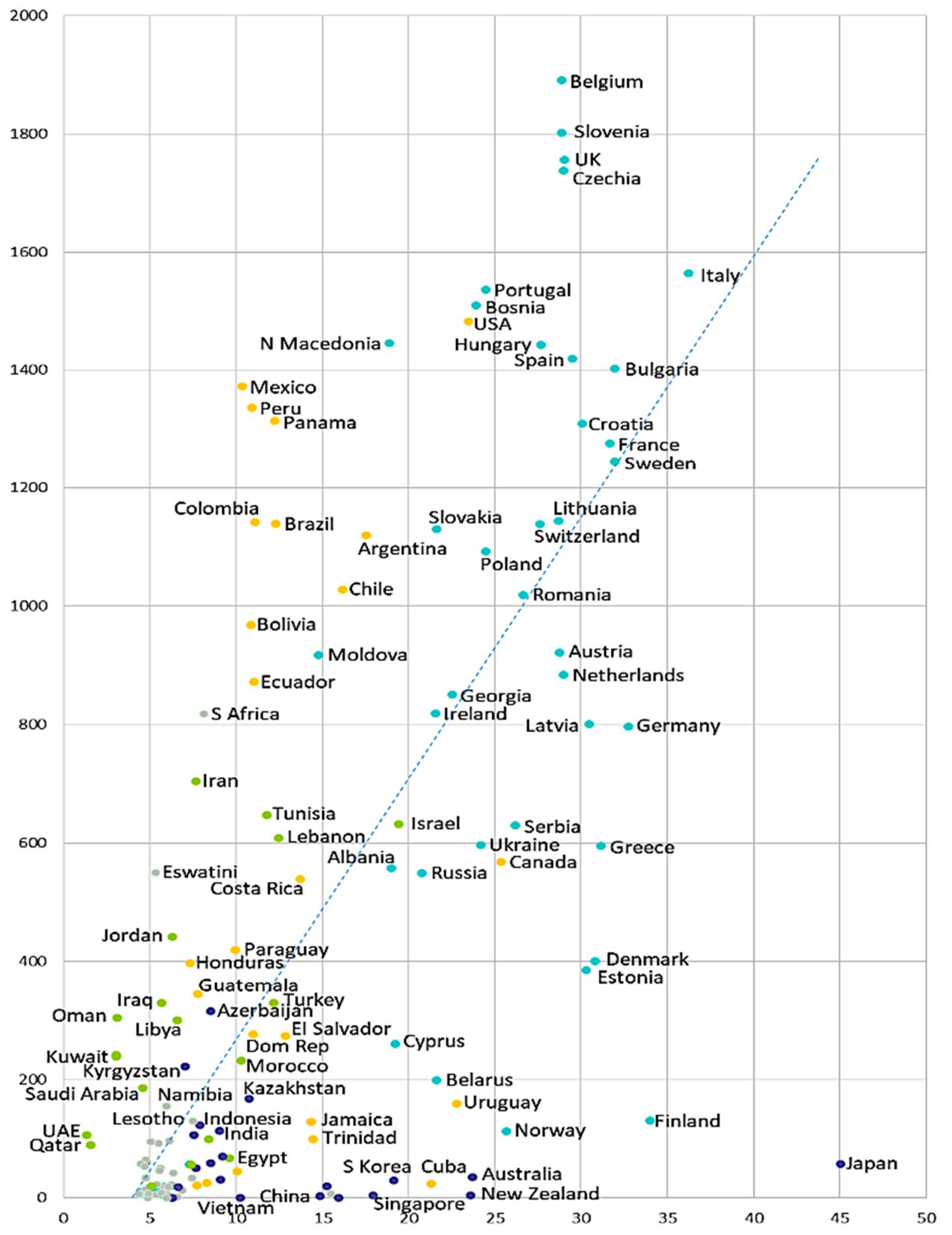

Figure 1: This analysis is based on data extracted from ourworldindata.org on 02/19/2021, retaining data on countries with populations of at-least 1 million, for which complete data were 
available for the analyses done. Among these countries, as one would expect, COVID-19 mortality is strongly correlated with age structure. Pearson's $\mathrm{R}^{2}$ for cumulative COVID-19 mortality and the ratio of persons aged $65+$ to those aged 15-64 is 0.401; in example, 40.15 of the between-country variance in cumulative COVID-19 mortality can be accounted for by age structure.

\section{Pre-existing Conditions}

From early on in the pandemic, it is well known that people with pre-existing conditions such as diabetes, chronic respiratory diseases, obesity, and hypertension have a greatly increased risk of moderate to severe complications from COVID-19 infection ${ }^{50,113,114}$. Broadly, these conditions are considerably less prevalent in low-income and middle-income countries (LICs and LMICs) when compared to higher income countries (HICs) ${ }^{9,115}$, providing an additional possible explanation for why COVID-19 burden is far reduced in the African continent. Indeed, African countries have low prevalence of NCDs (only accounting for 29.8\% of total burden of disease in SSA) ${ }^{116}$, compared to $88 \%$ in the US and $74 \%$ in Brazil ${ }^{117}$. which align with the impact of pre-existing conditions on increasingly severe complications and death from COVID-199,113. South Africa, which accounts for nearly $40 \%$ of all reported COVID-19 cases and half of deaths in the continent ${ }^{2}$, reports an exceptionally high burden of NCDs ${ }^{116,118}$. However, some research suggests that this apparent "trade off" of infectious disease for NCDs does not mitigate COVID-19 burden ${ }^{9,25}$.For instance, a recent cohort study in South Africa suggested that HIV was associated with a doubling of mortality risk from COVID-19 ${ }^{119}$. This is potentially significant to consider for explaining why South Africa has disproportionate COVID19 burden on the continent given it also has the greatest number of people living with HIV/AIDS in the world ${ }^{120}$. More studies are needed, however, before this potential association can be determined.

\section{Trained Immunity}

The phenomenon of trained immunity may be tempering the COVID-19 burden in the continent. Here, we focus on four elements underlying this hypothesis: (i) BCG vaccinations, (ii) exposure to varied commensal microorganisms, or the "hygiene hypothesis", (iii) prevalence of infectious diseases, and (iv) historical use of herbal plants and remedies.

(i) Live vaccines activate innate immune systems, conferring protection against future infections from other pathogens ${ }^{121-126}$, which researchers believe may have the potential to also attenuate consequences of infection with SARS-CoV-2 $2^{127}$. Recent data suggest that regions with mandated BCG vaccinations have had lower COVIID-19 disease burden ${ }^{128}$. Children vaccinated with BCG could have a lower infection risk with SARS-CoV-2 ${ }^{129}$, including well into adulthood. Interestingly, and applicable to COVID-19, BCG vaccination was shown to be especially protective against complications of other respiratory viral infections, supported by studies in Guinea-Bissau and South Africa ${ }^{130,131}$. Additionally, in rodent models, BCG reduces viral load from infection by influenza A and herpes simplex virus type 2 (HSV2) ${ }^{132,133}$, with a mediation by a boosted innate, nonspecific immune defense via increased cytokine production and macrophage action. It is not concretely known if BCG immunity confers such protection in older populations $^{129}$, but this has been suggested by some research ${ }^{134}$. This is hypothesized in part from observations in countries that lagged behind other efforts to get out BCG, such as Iran and 
Somalia, which have incurred a significant death toll from COVID-19;. Still, it is possible that countries with earlier BCG administration campaigns have contributed to the protection of older populations from heavy COVID-19 burden through childhood inoculation for tuberculosis ${ }^{134}$. Because COVID-19 complications are often a result from significant systemic inflammation ${ }^{135}$ the fact that inoculation with BCG boosts an innate immunity that subsequently lowers the extent of inflammation ${ }^{129}$ could be a pathway by which BCG attenuates infection with SARS-CoV-2. Of course, controlled clinical trials are needed to verify this hypothesis. While this varies, most African countries have high BCG coverage ${ }^{136}$, with the notable exception of Somalia due to the long-standing civil wars there interfering with child vaccination programs. As noted in one study, countries without universal policies for BCG vaccination (such as Italy, the U.K., Spain, and the U.S.) have experienced much more severe disease burden compared to countries with universal programs (including most African countries and Japan, for example) ${ }^{134}$. Furthermore, if this BCG hypothesis turns out to have some merit, countries in Africa with similar levels of BCG coverage and similar population structure should show similar COVID-19 burden.

(ii) The so-called "hygiene hypothesis" posits that some environments advantage populations against certain forms of infection and disease due to chronic exposure to a multimicrobial environment, potentially producing protective immune effects when encountering new potential pathogens ${ }^{127,137}$. There has been some concern regarding regions that use ultra-hygienic practices, exemplified by the overuse of hand sanitizer and other disinfection practices in many countries as inadvertently creating a disadvantage for confronting new immune challenges such as SARS-CoV-2 ${ }^{127}$. Accordingly, non-specific immunity would be weakened and may have implications for disrupting the adaptive composition of commensal organisms on the skin, gastrointestinal tract, and other organ systems ${ }^{127}$. Because COVID-19 is a relatively new viral problem, it may take a while before conclusive statements can be made about the role of the microbial environment on infection susceptibility, but researchers agree this hypothesis is plausible ${ }^{127}$, in part indicated by the aforementioned dichotomy of burden between richer and poorer countries ${ }^{138,139}$. Higher income countries (with a few exceptions) have suffered much greater COVID-19 burdens (specifically, hospitalization and death rates) than the poorest countries, on average ${ }^{2}$. Such data raises consideration that richer countries could be maladaptively over-sanitizing.

(iii) Given that 22 of the 25 most vulnerable countries to infectious diseases epidemics are in Africa (the other three being Afghanistan, Haiti and Yemen) ${ }^{140}$, the continent carries the heaviest burden of infectious diseases including the impoverishing neglected tropical diseases (NTDs) $)^{141,142}$. During 2018 alone, SSA faced 96 disease outbreaks in 36 of 47 countries $^{52}$. This pathogenic environment precipitates the wide use of antibiotics, antimalarials, and other drugs to treat NTDs such as azithromycin and ivermectin often distributed through mass drug administrations ${ }^{143-147}$, which might counteract to mitigate COVID-19 morbidity. In particular, used widely over several decades in SSA, ivermectin has been spotlighted as a potential treatment for COVID-19 $9^{148,149}$, including by the $\mathrm{NIH}^{150,151}$. Researchers have postulated that "circulating viruses or parasites in the African subcontinent" could explain high SARS-CoV-2 antibody seropositivity ${ }^{14}$. For instance, of 228 million cases of malaria worldwide in $2018,93 \%$ were in SSA ${ }^{152}$. Notably, South Africa is not generally endemic for malaria and other NTDs ${ }^{153}$. Intense malaria exposure (which is frequent in many rural areas in SSA and much less so in urban areas, and not at all in South Africa or North Africa) has a strong influence on the immune system and could contribute to a better trained immunity ${ }^{154,155}$. It is possible that infection by malaria alone may overstimulate the immune system and confer an immune 
advantage when compared to nonexposed populations. To further investigate this potential role, because very few to no communities outside of Africa are holo-endemic for the disease ${ }^{156}$, mechanistic studies would be needed to determine if there is cross-immunity between malaria and SARS-CoV-2 exposure.

(iv) Yet to be measured, historical use of natural medicine for primary care ${ }^{157-159}$ and widespread belief of self-medication with these for COVID-19 in Africa has triggered a WHOAFRO expert panel in September 2020 to endorse a protocol for clinical investigation of herbal medicine for COVID-19 ${ }^{160}$. During March 30-April 1, 2021, the Third Regional Consultation with Experts and Researchers on the Contribution of Traditional Medicine to COVID-19 Response in the African Region was held with contributions from scores of scientists and countries. The case for exploring natural medicine in the fight against COVID-19 is justified ${ }^{161}$. Although African countries such as Madagascar has endorsed wide use of a traditional therapeutic agent to fight COVID-19, there are no published scientific data that would lend support to this claim. Clinicaltrials.gov reports several studies underway including in Chinese traditional medicines ${ }^{162}$. The establishment in Africa of a Regional Expert Advisory Committee on Traditional Medicine for COVID-19 compromising 25 members speaks to the widespread use of and belief in herbal medicine as possible means of prevention or cure of COVID-19.

\section{Genetics}

Recent work suggests a role for genetics in COVID-19 trajectory and in differentially affecting separate populations ${ }^{163,164}$. Some genetic immunological factors could possibly be playing a role in shielding Africa from the brunt of the pandemic ${ }^{38}$. For example, SARS-CoV-2 infects human cells largely through its interactions with the ACE2 receptor, involved in regulating blood pressure dynamics ${ }^{6,114,165}$. Populations varying in expression of the ACE2 protein may have different baseline "openness" for infection. African people have been shown to respond less effectively to ACE inhibitors for treatment of blood pressure and have less expression of ACE2; therefore, there is potential for a more difficult route the virus must maneuver to infect cells in this population ${ }^{6,165}$. There also may be genetic susceptibility via the 3p21.31 gene cluster as one GWAS study showed ABO blood group A having the highest risk for COVID-19-associated respiratory failure, with group O having the lowest risk ${ }^{166}$. Studies have shown that African populations have a particularly high proportion of O-positivity at nearly $50 \%{ }^{167-169}$. It is possible that this increased O prevalence could be conferring a greater protective effect in African populations compared with other groups with less O prevalence; however, no studies have concluded this. While this hypothesis is somewhat challenged by the particularly heavy COVID-19 burden facing African Americans in the U.S. ${ }^{170}$, who would likely share some or most of these genetic advantages ${ }^{171,172}$, elevated levels of NCDs are observed more in African Americans than continental African populations ${ }^{116,173,174}$, which could help explain this discrepancy along with other socioeconomic and cultural factors.

\section{Broader Sociocultural Implications}

Importantly, inequality in distribution of income (standardized by the GINI co-efficient) appears to be at-least partially correlated with increasing disease burden from COVID-19 as South Africa (with a value of 63.1, among the highest in the world) and Brazil (54.7) ${ }^{175}$ have been hit hard by COVID-19. One study of the top 50 countries with the highest numbers of cases 
suggests that increased income inequality was associated with increased severe cases and mortality ${ }^{50}$. Across the US, Brazil, South Africa and Europe increased mortality has been reported among minority groups such as Africans and Asians ${ }^{176,177}$. Three countries (South Africa, Brazil, the U.S.) seem to have similar risk profiles with large black populations: long historical cleavages of institutional racism and inequality ${ }^{178,179}$ that exacerbate COVID-19 vulnerabilities among black populations. Which role inequality and poverty play depends totally on the behaviour and biological/immunological factors they influence. For example, in New York and other U.S. cities, poor people cannot isolate themselves and have lower social mobility ${ }^{180}$. In contrast, in many African cities, it is the social and political elites who can afford to live in airconditioned closed spaces, increasing susceptibility to infection ${ }^{181}$. However, this should not be generalized as the case in every African country, as work has also pointed to the similar theme of poorer populations facing higher burden, such as in South Africa, with the elites largely shielded from the virus ${ }^{182}$.

\section{Conclusion}

Relatively low severity and death due to COVID-19 in Africa presents a paradox ${ }^{38,39,183}$. Despite early doomsday predictions for Africa, the continent succeeded in stemming the first wave of SARS-CoV-2 ${ }^{184}$, although the second wave has been more severe ${ }^{21}$. On the whole, the factors discussed here have contributed to modulating disease spread and severity; however, the strength of evidence of each varies. A third wave may yet appear with more consequential morbidity and mortality impacts ${ }^{185}$ especially as early government measures have been relaxed in many countries ${ }^{21}$. Facing the lowest quality of health systems ${ }^{9,186}$, the continent will be challenged if it faces an excessive COVID-19 disease burden ${ }^{187}$. Estimates already show that many excess deaths especially in the SSA region will result not from COVID-19 but from disruptions in programs fighting malnutrition ${ }^{188}$, ${\mathrm{HIV} / \mathrm{AIDS}^{189} \text {, malaria }}^{190}$, maternal and child health deaths ${ }^{32}$, and implementation of immunization programs ${ }^{191}$. Therefore, a range of policy options taking this into account as well as economic and socio-cultural characteristics including the expected benefits and harms of control measures (e.g., on education and livelihoods) ${ }^{7,39}$ need to be implemented.

It is likely that SARS-CoV-2 has already been widely disseminated through Africa, yet evidently without having had the severe consequences of COVID-19 burden such as the significant uptick in hospitalizations and deaths that many other regions have experienced ${ }^{25}$. If so, widespread infection is likely to also result in widespread natural immunity ${ }^{192}$. While the true picture of infections and mortality in the continent has yet to fully emerge, the quality of data for other diseases such as HIV/AIDS indicate that Africa has capacity to collect and report valid disease surveillance data ${ }^{193}$, which should give a degree of confidence on the COVID-19 data from the continent. Nevertheless, improving completeness of data collection and reporting is an ongoing mission for Africa and elsewhere ${ }^{30,194}$. Strengthening lab capacities, validating current rapid tests in context of other infectious diseases, and standardizing data and survey reporting will also expand the true picture ${ }^{39}$. Additionally, before the COVID-19 pandemic in 2019 researchers and policy makers from Africa called for a new model for public health in the $21^{\text {st }}$ century precisely to prepare for this kind of pandemic ${ }^{195}$. Now, as the pandemic evolves and vaccine rollout accelerates, the experience in Africa may offer salient lessons for the rest of the world given its long experience with infectious diseases and outbreak readiness ${ }^{53,54}$. 


\section{Contribution \\ Conceptualization, WVD, DA, DH, RCB, SH, RGW; Design \& Analysis, RGW, JLH, WVD, DA, DH, RCB, SH, UA, MA; Writing, Review \& Editing, RGW, JLH, WVD, DA, DH, RCB, $\mathrm{SH}, \mathrm{UA}, \mathrm{MA}$; Visualization, SH. All authors read and approved the final manuscript.}

\section{Conflicts of Interest}

The authors declare no conflict of interest.

\section{Acknowledgements}

We would like to recognize Daniel Halperin, Mead Over, Norman Hearst, and Alan Whiteside for their contributions to this manuscript.

\section{References}

1. Coronavirus Disease 2019 (COVID-19) Dashboard. Africa Centres for Disease Control and Prevention. https://africacdc.org/covid-19/. Accessed 04/08/2021.

2. COVID-19 Dashboard. Johns Hopkins University. https://coronavirus.jhu.edu/map.html. Accessed 04/08/2021.

3. World Population Prospects 2019. United Nations, Department of Economic and Social Affairs, Population Division. In.

4. El-Sadr WM, Justman J. Africa in the Path of Covid-19. N Engl J Med. 2020;383(3):e11.doi:10.1056/NEJMp2008193

5. Pearson CA, Van Schalkwyk C, Foss AM, et al. Projected early spread of COVID-19 in Africa through 1 June 2020. Euro Surveill. 2020;25(18).doi:10.2807/15607917.ES.2020.25.18.2000543

6. Quaresima V, Naldini MM, Cirillo DM. The prospects for the SARS-CoV-2 pandemic in Africa. EMBO Mol Med. 2020;12(6):e12488.doi:10.15252/emmm.202012488

7. Mueller V, Sheriff G, Keeler C, Jehn M. COVID-19 Policy Modeling in Sub-Saharan Africa. Applied Economic Perspectives and Policy. 2021;43(1):2438.doi:https://doi.org/10.1002/aepp.13078

8. Gilbert M, Pullano G, Pinotti F, et al. Preparedness and vulnerability of African countries against importations of COVID-19: a modelling study. The Lancet. 2020;395(10227):871-877.doi:10.1016/S0140-6736(20)30411-6

9. Walker PGT, Whittaker C, Watson OJ, et al. The impact of COVID-19 and strategies for mitigation and suppression in low- and middle-income countries. Science. 2020;369(6502):413-422.doi:10.1126/science.abc0035

10. Fokoua-Maxime DC, Amor-Ndjabo M, Ankobil A, Victor-Kiyung M, Franck-Metomb S, Choukem SP. Does sub-Saharan Africa truly defy the forecasts of the COVID-19 pandemic? Response from population data. medRxiv. 2020:2020.2007.2006.20147124.doi:10.1101/2020.07.06.20147124

11. Dzinamarira T, Dzobo M, Chitungo I. COVID-19: A perspective on Africa's capacity and response. J Med Virol. 2020;92(11):2465-2472.doi:10.1002/jmv.26159

12. Ogunleye OO, Basu D, Mueller D, et al. Response to the Novel Corona Virus (COVID19) Pandemic Across Africa: Successes, Challenges, and Implications for the Future. Front Pharmacol. 2020;11:1205.doi:10.3389/fphar.2020.01205 
13. Mulenga LB, Hines JZ, Fwoloshi S, et al. Prevalence of SARS-CoV-2 in six districts in Zambia in July, 2020: a cross-sectional cluster sample survey. The Lancet Global Health. 2021.doi:10.1016/S2214-109X(21)00053-X

14. Nkuba Ndaye A, Hoxha A, Madinga J, et al. Challenges in interpreting SARS-CoV-2 serological results in African countries. The Lancet Global Health. 2021.doi:10.1016/S2214-109X(21)00060-7

15. Olayanju O, Bamidele O, Edem F, et al. SARS-CoV-2 Seropositivity in Asymptomatic Frontline Health Workers in Ibadan, Nigeria. Am J Trop Med Hyg. 2021;104(1):9194.doi:10.4269/ajtmh.20-1235

16. Chibwana MG, Jere KC, Kamn'gona R, et al. High SARS-CoV-2 seroprevalence in Health Care Workers but relatively low numbers of deaths in urban Malawi. medRxiv. 2020:2020.2007.2030.20164970.doi:10.1101/2020.07.30.20164970

17. Uyoga S, Adetifa IMO, Karanja HK, et al. Seroprevalence of anti-SARS-CoV-2 IgG antibodies in Kenyan blood donors. Science. 2021;371(6524):7982.doi:10.1126/science.abe 1916

18. Sykes W, Mhlanga L, Swanevelder R, et al. Prevalence of anti-SARS-CoV-2 antibodies among blood donors in Northern Cape, KwaZulu-Natal, Eastern Cape, and Free State provinces of South Africa in January 2021. Res Sq. 2021.doi:10.21203/rs.3.rs-233375/v1

19. Shaw JA, Meiring M, Cummins T, et al. Higher SARS-CoV-2 seroprevalence in workers with lower socioeconomic status in Cape Town, South Africa. PLoS One. 2021;16(2):e0247852.doi:10.1371/journal.pone.0247852

20. Milleliri JM, Coulibaly D, Nyobe B, et al. SARS-CoV-2 Infection in Ivory Coast: A Serosurveillance Survey among Gold Mine Workers. Am J Trop Med Hyg. 2021.doi:10.4269/ajtmh.21-0081

21. Salyer SJ, Maeda J, Sembuche S, et al. The first and second waves of the COVID-19 pandemic in Africa: a cross-sectional study. The Lancet. 2021;397(10281):12651275.doi:https://doi.org/10.1016/S0140-6736(21)00632-2

22. Usuf E, Roca A. Seroprevalence surveys in sub-Saharan Africa: what do they tell us? The Lancet Global Health. 2021.doi:10.1016/S2214-109X(21)00092-9

23. Tso FY, Lidenge SJ, Pena PB, et al. High prevalence of pre-existing serological crossreactivity against severe acute respiratory syndrome coronavirus-2 (SARS-CoV-2) in sub-Saharan Africa. Int J Infect Dis. 2021;102:577-583.doi:10.1016/j.ijid.2020.10.104

24. Yadouleton A, Sander AL, Moreira-Soto A, et al. Limited Specificity of Serologic Tests for SARS-CoV-2 Antibody Detection, Benin. Emerg Infect Dis. 2021;27(1).doi:10.3201/eid2701.203281

25. Wang L, Dong S, Zhao Y, et al. Epidemic Characteristics of COVID-19 in Africa. Frontiers in Physics. 2020;8(392).doi:10.3389/fphy.2020.564698

26. Chanda-Kapata P, Kapata N, Zumla A. COVID-19 and malaria: A symptom screening challenge for malaria endemic countries. Int J Infect Dis. 2020;94:151153.doi:10.1016/j.ijid.2020.04.007

27. Jacobs J, Kühne V, Lunguya O, Affolabi D, Hardy L, Vandenberg O. Implementing COVID-19 (SARS-CoV-2) Rapid Diagnostic Tests in Sub-Saharan Africa: A Review. Front Med (Lausanne). 2020;7:557797-557797.doi:10.3389/fmed.2020.557797

28. Maclean R. A Continent Where the Dead Are Not Counted. The New York Times. $01 / 02 / 2021$. 
29. Report on the status of civil registration and vital statistics in Africa. Economic Commission for Africa;2017.

30. Karlinsky A, Kobak D. The World Mortality Dataset: Tracking excess mortality across countries during the COVID-19 pandemic. medRxiv. 2021:2021.2001.2027.21250604.doi:10.1101/2021.01.27.21250604

31. Cardoso K. Measuring Africa's Data Gap: The cost of not counting the dead. $B B C$. 02/22/2021.

32. Roberton T, Carter ED, Chou VB, et al. Early estimates of the indirect effects of the COVID-19 pandemic on maternal and child mortality in low-income and middle-income countries: a modelling study. The Lancet Global Health. 2020;8(7):e901e908.doi:10.1016/S2214-109X(20)30229-1

33. Revealing the toll of COVID-19: A technical package for Member States. Africa Centres for Disease Control and Prevention; 06/22/2020.

34. Setel P, AbouZahr C, Atuheire EB, et al. Mortality surveillance during the COVID-19 pandemic. Bull World Health Organ. 2020;98(6):374.doi:10.2471/BLT.20.263194

35. Post LA, Argaw ST, Jones C, et al. A SARS-CoV-2 Surveillance System in Sub-Saharan Africa: Modeling Study for Persistence and Transmission to Inform Policy. J Med Internet Res. 2020;22(11):e24248.doi:10.2196/24248

36. Rapid mortality surveillance for COVID-19 in West Africa. African Field Epidemiology Network (AFENET). http://www.afenet.net/index.php/news/news/849-rapid-mortalitysurveillance-for-covid-19-in-west-africa. Updated 12/09/2020. Accessed 04/08/2021.

37. Mehtar S, Preiser W, Lakhe NA, et al. Limiting the spread of COVID-19 in Africa: one size mitigation strategies do not fit all countries. The Lancet Global Health. 2020;8(7):e881-e883.doi:10.1016/S2214-109X(20)30212-6

38. Ghosh D, Bernstein JA, Mersha TB. COVID-19 pandemic: The African paradox. J Glob Health. 2020;10(2):020348.doi:10.7189/jogh.10.020348

39. Maeda JM, Nkengasong JN. The puzzle of the COVID-19 pandemic in Africa. Science. 2021;371(6524):27-28.doi:10.1126/science.abf8832

40. Mukherjee S. Why does the pandemic seem to be hitting some countries harder than others? In. The New Yorker.

41. Leonhardt D. A Covid Mystery. The New York Times. 03/08/2021.

42. Van Damme W, Dahake R, Delamou A, et al. The COVID-19 pandemic: diverse contexts; different epidemics - how and why? BMJ Global Health. 2020;5(7):e003098.doi:10.1136/bmjgh-2020-003098

43. Van Damme W, Dahake R, van de Pas R, Vanham G, Assefa Y. COVID-19: Does the infectious inoculum dose-response relationship contribute to understanding heterogeneity in disease severity and transmission dynamics? Medical Hypotheses. 2021;146:110431.doi:https://doi.org/10.1016/j.mehy.2020.110431

44. Cabore JW, Karamagi HC, Kipruto H, et al. The potential effects of widespread community transmission of SARS-CoV-2 infection in the World Health Organization African Region: a predictive model. BMJ Global Health. 2020;5(5):e002647.doi:10.1136/bmjgh-2020-002647

45. Achoki T, Alam U, Were L, et al. COVID-19 pandemic in the African continent: Forecasts of cumulative cases, new infections, and mortality. medRxiv. 2020:2020.2004.2009.20059154.doi:10.1101/2020.04.09.20059154 
46. Kuguyo O, Kengne AP, Dandara C. Singapore COVID-19 Pandemic Response as a Successful Model Framework for Low-Resource Health Care Settings in Africa? OMICS. 2020;24(8):470-478.doi:10.1089/omi.2020.0077

47. Lone SA, Ahmad A. COVID-19 pandemic - an African perspective. Emerg Microbes Infect. 2020;9(1):1300-1308.doi:10.1080/22221751.2020.1775132

48. Gaye B, Khoury S, Cene CW, et al. Socio-demographic and epidemiological consideration of Africa's COVID-19 response: what is the possible pandemic course? Nat Med. 2020;26(7):996-999.doi:10.1038/s41591-020-0960-y

49. Moore J. What African nations are teaching the west about fighting the coronavirus. In. The New Yorker.

50. Chaudhry R, Dranitsaris G, Mubashir T, Bartoszko J, Riazi S. A country level analysis measuring the impact of government actions, country preparedness and socioeconomic factors on COVID-19 mortality and related health outcomes. EClinicalMedicine. 2020;25.doi:10.1016/j.eclinm.2020.100464

51. Rice BL, Annapragada A, Baker RE, et al. Variation in SARS-CoV-2 outbreaks across sub-Saharan Africa. Nature Medicine. 2021;27(3):447-453.doi:10.1038/s41591-02101234-8

52. Mboussou F, Ndumbi P, Ngom R, et al. Infectious disease outbreaks in the African region: overview of events reported to the World Health Organization in 2018 ERRATUM. Epidemiol Infect. 2019;147:e307.doi:10.1017/S0950268819002061

53. Alam U, Nabyonga-Orem J, Mohammed A, Malac DR, Nkengasong JN, Moeti MR. Redesigning health systems for global heath security. The Lancet Global Health. 2021;9(4):e393-e394.doi:10.1016/S2214-109X(20)30545-3

54. Holst C, Sukums F, Radovanovic D, Ngowi B, Noll J, Winkler AS. Sub-Saharan Africa\&\#x2014; the new breeding ground for global digital health. The Lancet Digital Health. 2020;2(4):e160-e162.doi:10.1016/S2589-7500(20)30027-3

55. Wilkinson A, Parker M, Martineau F, Leach M. Engaging 'communities': anthropological insights from the West African Ebola epidemic. Philos Trans R Soc Lond B Biol Sci. 2017;372(1721).doi:10.1098/rstb.2016.0305

56. Laverack G, Manoncourt E. Key experiences of community engagement and social mobilization in the Ebola response. Glob Health Promot. 2016;23(1):7982.doi:10.1177/1757975915606674

57. Shuaib F, Gunnala R, Musa EO, et al. Ebola virus disease outbreak - Nigeria, JulySeptember 2014. MMWR Morb Mortal Wkly Rep. 2014;63(39):867-872.

https://www.ncbi.nlm.nih.gov/pubmed/25275332

https://www.ncbi.nlm.nih.gov/pmc/articles/PMC4584877/pdf/867-872.pdf. Published 2014/10/03.

58. Slutkin G, Okware S, Naamara W, et al. How Uganda Reversed Its HIV Epidemic. AIDS and Behavior. 2006;10(4):351-360.doi:10.1007/s10461-006-9118-2

59. Al-Hasan A, Yim D, Khuntia J. Citizens' Adherence to COVID-19 Mitigation Recommendations by the Government: A 3-Country Comparative Evaluation Using Web-Based Cross-Sectional Survey Data. J Med Internet Res. 2020;22(8):e20634.doi:10.2196/20634

60. Margraf J, Brailovskaia J, Schneider S. Behavioral measures to fight COVID-19: An 8country study of perceived usefulness, adherence and their predictors. PLoS One. 2020;15(12):e0243523.doi:10.1371/journal.pone.0243523 
61. LSMS-Supported High-Frequency Phone Surveys on COVID-19. The World Bank. https://papers.ssrn.com/sol3/papers.cfm?abstract_id=3675884. Accessed 04/08/2021.

62. Isah MB, Abdulsalam M, Bello A, et al. Coronavirus Disease 2019 (COVID-19): Knowledge, attitudes, practices (KAP) and misconceptions in the general population of Katsina State, Nigeria. medRxiv. 2020:2020.2006.2011.20127936.doi:10.1101/2020.06.11.20127936

63. Banda J, Dube AN, Brumfield S, et al. Knowledge, risk perceptions and behaviors related to the COVID-19 pandemic in Malawi. medRxiv. 2020:2020.2006.2016.20133322.doi:10.1101/2020.06.16.20133322

64. Defar A, Molla G, Abdella S, et al. Knowledge, practice and associated factors towards the prevention of COVID-19 among high-risk groups: A cross-sectional study in Addis Ababa, Ethiopia. PLoS One. 2021;16(3):e0248420.doi:10.1371/journal.pone.0248420

65. Serwaa D, Lamptey E, Appiah AB, Senkyire EK, Ameyaw JK. Knowledge, risk perception and preparedness towards coronavirus disease-2019 (COVID-19) outbreak among Ghanaians: a quick online cross-sectional survey. Pan Afr Med J. 2020;35(Suppl 2):44.doi:10.11604/pamj.supp.2020.35.2.22630

66. Ditekemena JD, Nkamba DM, Muhindo HM, et al. Factors associated with adherence to COVID-19 prevention measures in the Democratic Republic of the Congo (DRC): results of an online survey. BMJ open. 2021;11(1):e043356-e043356.doi:10.1136/bmjopen2020-043356

67. Hedima EW, Michael SA, David EA. Knowledge and Risk Perception of The Novel Coronavirus Disease 2019 Among Adult Nigerians: A Cross-Sectional Study. medRxiv. 2020:2020.2008.2023.20180141.doi:10.1101/2020.08.23.20180141

68. Olum R, Chekwech G, Wekha G, Nassozi DR, Bongomin F. Coronavirus Disease-2019: Knowledge, Attitude, and Practices of Health Care Workers at Makerere University Teaching Hospitals, Uganda. Front Public Health. 2020;8:181.doi:10.3389/fpubh.2020.00181

69. Rader B, Scarpino SV, Nande A, et al. Crowding and the shape of COVID-19 epidemics. Nature Medicine. 2020;26(12):1829-1834.doi:10.1038/s41591-020-1104-0

70. Nadini M, Zino L, Rizzo A, Porfiri M. A multi-agent model to study epidemic spreading and vaccination strategies in an urban-like environment. Appl Netw Sci. 2020;5(1):6868.doi:10.1007/s41109-020-00299-7

71. Nkalu CN, Edeme RK, Nchege J, Arazu OW. Rural-Urban Population Growth, Economic Growth and Urban Agglomeration in Sub-Saharan Africa: What Does Williamson-Kuznets Hypothesis Say? Journal of Asian and African Studies. 2019;54(8):1247-1261.doi:10.1177/0021909619865997

72. World Urbanization Prospects 2018. United Nations. Department of Economic and Social Affairs. Population Dynamics. https://population.un.org/wup/Country-Profiles/. Accessed 04/08/2021.

73. Diop BZ, Ngom M, Pougué Biyong C, Pougué Biyong JN. The relatively young and rural population may limit the spread and severity of COVID-19 in Africa: a modelling study. BMJ Global Health. 2020;5(5):e002699.doi:10.1136/bmjgh-2020-002699

74. Chirisa I, Mutambisi T, Chivenge M, Mabaso E, Matamanda AR, Ncube R. The urban penalty of COVID-19 lockdowns across the globe: manifestations and lessons for Anglophone sub-Saharan Africa. GeoJournal. 2020.doi:10.1007/s10708-020-10281-6 
75. Yang W, Zhang W, Kargbo D, et al. Transmission network of the 2014\&\#x2013;2015 Ebola epidemic in Sierra Leone. Journal of The Royal Society Interface. 2015;12(112):20150536.doi:doi:10.1098/rsif.2015.0536

76. Kiti MC, Kinyanjui TM, Koech DC, Munywoki PK, Medley GF, Nokes DJ. Quantifying age-related rates of social contact using diaries in a rural coastal population of Kenya. PloS one. 2014;9(8):e104786-e104786.doi:10.1371/journal.pone.0104786

77. Mossong J, Hens N, Jit M, et al. Social contacts and mixing patterns relevant to the spread of infectious diseases. PLoS Med. 2008;5(3):e74.doi:10.1371/journal.pmed.0050074

78. Fraser T, Aldrich DP. The dual effect of social ties on COVID-19 spread in Japan. Scientific Reports. 2021;11(1):1596.doi:10.1038/s41598-021-81001-4

79. Fraser T. Japanese social capital and social vulnerability indices: Measuring drivers of community resilience 2000-2017. International Journal of Disaster Risk Reduction. 2021;52:101965.doi:https://doi.org/10.1016/j.ijdrr.2020.101965

80. Imbulana Arachchi J, Managi S. The role of social capital in COVID-19 deaths. BMC Public Health. 2021;21(1):434.doi:10.1186/s12889-021-10475-8

81. Cash R, Patel V. Has COVID-19 subverted global health? The Lancet. 2020;395(10238):1687-1688.doi:10.1016/S0140-6736(20)31089-8

82. Sugg MM, Spaulding TJ, Lane SJ, et al. Mapping community-level determinants of COVID-19 transmission in nursing homes: A multi-scale approach. Sci Total Environ. 2021;752:141946-141946.doi:10.1016/j.scitotenv.2020.141946

83. Otieno S. COVID-19: Africa's eldery may benefit from social structures. scidev.net. https://www.scidev.net/sub-saharan-africa/news/covid-19-africa-s-elderly-may-benefitfrom-social-structures/. Accessed 04/08/2021.

84. Lloyd-Sherlock P, Ebrahim S, Geffen L, McKee M. Bearing the brunt of covid-19: older people in low and middle income countries. $B M J$.

2020;368:m1052.doi:10.1136/bmj.m1052

85. Cowper B, Jassat W, Pretorius P, et al. COVID-19 in long-term care facilities in South Africa: No time for complacency. S Afr Med J. 2020;110(10):962-

963.doi:10.7196/SAMJ.2020.v110i10.15214

86. Adamek MEB, S. LONG TERM CARE FOR ELDERS IN DEVELOPING COUNTRIES IN ASIA AND AFRICA: A SYSTEMATIC REVIEW. The Gerontologist. 2016;56(Suppl_3):413-413.doi:10.1093/geront/gnw162.1650

87. Cafagna GA, Natalia; Ibarrarán, Pablo; Oliveri, María Laura; Medellín, Nadin; Stampini, Marco. Age with Care: Long-term Care in Latin America and the Caribbean. In: Bank I$\mathrm{AD}$, ed2019.

88. Caruso MG, Sebastian; Ibarrarán, Pablo. Long-Term Care in Latin America and the Carribean? Theory and Policy Considerations. National Bureau of Economic Research.doi:10.3386/w23797

89. World Health Organization. Modes of transmission of virus causing COVID-19: implications for IPC precaution recommendations. https://www.who.int/news$\mathrm{room} /$ commentaries/detail/modes-of-transmission-of-virus-causing-covid-19implications-for-ipc-precaution-recommendations. Updated 03/29/2020. Accessed 04/08/2021. 
90. Dietz L, Horve PF, Coil DA, Fretz M, Eisen JA, Van Den Wymelenberg K. 2019 Novel Coronavirus (COVID-19) Pandemic: Built Environment Considerations To Reduce Transmission. mSystems. 2020;5(2).doi:10.1128/mSystems.00245-20

91. Setti L, Passarini F, De Gennaro G, et al. SARS-Cov-2RNA found on particulate matter of Bergamo in Northern Italy: First evidence. Environ Res. 2020;188:109754.doi:10.1016/j.envres.2020.109754

92. Bulfone TC, Malekinejad M, Rutherford GW, Razani N. Outdoor Transmission of SARS-CoV-2 and Other Respiratory Viruses: A Systematic Review. J Infect Dis. 2021;223(4):550-561.doi:10.1093/infdis/jiaa742

93. Senatore V, Zarra T, Buonerba A, et al. Indoor versus outdoor transmission of SARSCOV-2: environmental factors in virus spread and underestimated sources of risk. EuroMediterr J Environ Integr. 2021;6(1):30-30.doi:10.1007/s41207-021-00243-w

94. Rowe BR, Canosa A, Drouffe JM, Mitchell JBA. Simple quantitative assessment of the outdoor versus indoor airborne transmission of viruses and covid-19. medRxiv. 2021:2020.2012.2030.20249058.doi:10.1101/2020.12.30.20249058

95. Naddeo V, Liu H. Editorial Perspectives: 2019 novel coronavirus (SARS-CoV-2): what is its fate in urban water cycle and how can the water research community respond? Environmental Science: Water Research \& Technology. 2020;6(5):12131216.doi:10.1039/D0EW90015J

96. Klepeis NE, Nelson WC, Ott WR, et al. The National Human Activity Pattern Survey (NHAPS): a resource for assessing exposure to environmental pollutants. J Expo Anal Environ Epidemiol. 2001;11(3):231-252.doi:10.1038/sj.jea.7500165

97. Matz CJ, Stieb DM, Brion O. Urban-rural differences in daily time-activity patterns, occupational activity and housing characteristics. Environ Health. 2015;14:88.doi:10.1186/s12940-015-0075-y

98. Merow C, Urban MC. Seasonality and uncertainty in global COVID-19 growth rates. Proc Natl Acad Sci U S A. 2020;117(44):27456-27464.doi:10.1073/pnas.2008590117

99. Wang J, Tang K, Feng K, et al. Impact of temperature and relative humidity on the transmission of COVID-19: a modelling study in China and the United States. BMJ Open. 2021;11(2):e043863.doi:10.1136/bmjopen-2020-043863

100. Kerr GH, Badr HS, Gardner LM, Perez-Saez J, Zaitchik BF. Associations between meteorology and COVID-19 in early studies: Inconsistencies, uncertainties, and recommendations. One Health. 2021;12:100225.doi:10.1016/j.onehlt.2021.100225

101. Rhodes JM, Subramanian S, Laird E, Kenny RA. Letter: low population mortality from COVID-19 in countries south of latitude $35^{\circ}$ North supports vitamin D as a factor determining severity. Authors' reply. Aliment Pharmacol Ther. 2020;52(2):412413.doi:10.1111/apt.15823

102. Pereira M, Dantas Damascena A, Galvão Azevedo LM, de Almeida Oliveira T, da Mota Santana J. Vitamin D deficiency aggravates COVID-19: systematic review and metaanalysis. Crit Rev Food Sci Nutr. 2020:1-9.doi:10.1080/10408398.2020.1841090

103. ClinicalTrials.gov. https://clinicaltrials.gov/ct2/results?recrs=\&cond=Vitamin + D\&term=Covid$19 \&$ cntry $=\&$ state $=\&$ city $=\&$ dist $=$. Accessed 04/08/2021.

104. Levin AT, Hanage WP, Owusu-Boaitey N, Cochran KB, Walsh SP, Meyerowitz-Katz G. Assessing the age specificity of infection fatality rates for COVID-19: systematic review, 
meta-analysis, and public policy implications. Eur J Epidemiol. 2020;35(12):11231138.doi:10.1007/s10654-020-00698-1

105. Risk for COVID-19 Infection, Hospitalization, and Death by Age Group. Centers for Disease Control and Prevention (CDC). https://www.cdc.gov/coronavirus/2019ncov/covid-data/investigations-discovery/hospitalization-death-by-age.html. Updated 02/18/2021. Accessed 04/08/2021.

106. Williamson EJ, Walker AJ, Bhaskaran K, et al. Factors associated with COVID-19related death using OpenSAFELY. Nature. 2020;584(7821):430436.doi:10.1038/s41586-020-2521-4

107. Census of India. Office of the Registrar General and Census Commissioner, India. https://censusindia.gov.in. Accessed 04/08/2021.

108. Projections and estimates of the population of Brazil. Brazil Institute of Geography and Statistics. https://www.ibge.gov.br/apps/populacao/projecao/index.html. Accessed 04/08/2021.

109. People and Population Data - United States of America. . United States Census Bureau. https://data.census.gov/cedsci/profile?g=0100000US. Accessed 04/08/2021.

110. United Kingdom 2011 Census Data. Office for National Statistics, United Kingdom. https://www.ons.gov.uk/census/2011census/2011censusdata. Accessed 04/08/2021.

111. Lawal Y. Africa's low COVID-19 mortality rate: A paradox? Int J Infect Dis. 2021;102:118-122.doi:10.1016/j.ijid.2020.10.038

112. COVID-19 Data Explorer. Oxford. https://ourworldindata.org/coronavirus. Accessed 2/19/2021.

113. Zhou F, Yu T, Du R, et al. Clinical course and risk factors for mortality of adult inpatients with COVID-19 in Wuhan, China: a retrospective cohort study. The Lancet. 2020;395(10229):1054-1062.doi:10.1016/S0140-6736(20)30566-3

114. Chakafana G, Mutithu D, Hoevelmann J, Ntusi N, Sliwa K. Interplay of COVID-19 and cardiovascular diseases in Africa: an observational snapshot. Clin Res Cardiol. 2020;109(12):1460-1468.doi:10.1007/s00392-020-01720-y

115. Hughes GD, Mbamalu ON, Okonji CO, Puoane TR. The Impact of Health Disparities on COVID-19 Outcomes: Early Findings from a High-Income Country and Two MiddleIncome Countries. J Racial Ethn Health Disparities. 2021:1-8.doi:10.1007/s40615-02100999-5

116. Gouda HN, Charlson F, Sorsdahl K, et al. Burden of non-communicable diseases in subSaharan Africa, 1990-2017: results from the Global Burden of Disease Study 2017. Lancet Glob Health. 2019;7(10):e1375-e1387.doi:10.1016/s2214-109x(19)30374-2

117. Noncommunicable diseases country profile 2018. World Health Organization.

118. Osetinsky B, Hontelez JAC, Lurie MN, et al. Epidemiological And Health Systems Implications Of Evolving HIV And Hypertension In South Africa And Kenya. Health Aff (Millwood). 2019;38(7):1173-1181.doi:10.1377/hlthaff.2018.05287

119. Davies M-A. HIV and risk of COVID-19 death: a population cohort study from the Western Cape Province, South Africa. medRxiv : the preprint server for health sciences. 2020:2020.2007.2002.20145185.doi:10.1101/2020.07.02.20145185

120. HIV and AIDS Estimates. South Africa 2019 Country Factsheet. UNAIDS. https://www.unaids.org/en/regionscountries/countries/southafrica. Accessed 04/08/2021.

121. Lee YJ, Lee JY, Jang YH, Seo S-U, Chang J, Seong BL. Non-specific Effect of Vaccines: Immediate Protection against Respiratory Syncytial Virus Infection by a Live 
Attenuated Influenza Vaccine. Front Microbiol. 2018;9:83-

83.doi:10.3389/fmicb.2018.00083

122. Uthayakumar D, Paris S, Chapat L, Freyburger L, Poulet H, De Luca K. Non-specific Effects of Vaccines Illustrated Through the BCG Example: From Observations to Demonstrations. Front Immunol. 2018;9:2869-2869.doi:10.3389/fimmu.2018.02869

123. Benn CS, Netea MG, Selin LK, Aaby P. A small jab - a big effect: nonspecific immunomodulation by vaccines. Trends Immunol. 2013;34(9):431439.doi:10.1016/j.it.2013.04.004

124. Parmar K, Siddiqui A, Nugent K. Bacillus Calmette-Guerin Vaccine and Nonspecific Immunity. The American Journal of the Medical

Sciences.doi:10.1016/j.amjms.2021.03.003

125. Blok BA, Arts RJ, van Crevel R, Benn CS, Netea MG. Trained innate immunity as underlying mechanism for the long-term, nonspecific effects of vaccines. J Leukoc Biol. 2015;98(3):347-356.doi:10.1189/jlb.5RI0315-096R

126. Clem AS. Fundamentals of vaccine immunology. J Glob Infect Dis. 2011;3(1):7378.doi:10.4103/0974-777X.77299

127. Sehrawat S, Rouse BT. Does the hygiene hypothesis apply to COVID-19 susceptibility? Microbes Infect. 2020;22(9):400-402.doi:10.1016/j.micinf.2020.07.002

128. Gursel M, Gursel I. Is global BCG vaccination-induced trained immunity relevant to the progression of SARS-CoV-2 pandemic? Allergy. 2020;75(7):18151819.doi:https://doi.org/10.1111/all.14345

129. O'Neill LAJ, Netea MG. BCG-induced trained immunity: can it offer protection against COVID-19? Nature Reviews Immunology. 2020;20(6):335-337.doi:10.1038/s41577-0200337-y

130. Stensballe LG, Nante E, Jensen IP, et al. Acute lower respiratory tract infections and respiratory syncytial virus in infants in Guinea-Bissau: a beneficial effect of BCG vaccination for girls community based case-control study. Vaccine. 2005;23(10):12511257.doi:10.1016/j.vaccine.2004.09.006

131. Nemes E, Geldenhuys H, Rozot V, et al. Prevention of M. tuberculosis Infection with H4:IC31 Vaccine or BCG Revaccination. New England Journal of Medicine. 2018;379(2):138-149.doi:10.1056/NEJMoa1714021

132. Spencer JC, Ganguly R, Waldman RH. Nonspecific protection of mice against influenza virus infection by local or systemic immunization with Bacille Calmette-Guérin. J Infect Dis. 1977;136(2):171-175.doi:10.1093/infdis/136.2.171

133. Starr SE, Visintine AM, Tomeh MO, Nahmias AJ. Effects of immunostimulants on resistance of newborn mice to herpes simplex type 2 infection. Proc Soc Exp Biol Med. 1976;152(1):57-60.doi:10.3181/00379727-152-39327

134. Miller A, Reandelar MJ, Fasciglione K, Roumenova V, Li Y, Otazu GH. Correlation between universal BCG vaccination policy and reduced morbidity and mortality for COVID-19: an epidemiological study. medRxiv. 2020:2020.2003.2024.20042937.doi:10.1101/2020.03.24.20042937

135. Manjili RH, Zarei M, Habibi M, Manjili MH. COVID-19 as an Acute Inflammatory Disease. The Journal of Immunology. 2020;205(1):12-19.doi:10.4049/jimmunol.2000413

136. Reported estimates of BCG coverage. World Health Organization. https://apps.who.int/immunization_monitoring/globalsummary/timeseries/tscoveragebcg. html. Updated 10/15/2020. Accessed 04/08/2021. 
137. Hadley C. Should auld acquaintance be forgot.... EMBO reports. 2004;5(12):11221124.doi:https://doi.org/10.1038/sj.embor.7400308

138. Chatterjee B, Karandikar RL, Mande SC. Paradoxical Case Fatality Rate dichotomy of Covid-19 among rich and poor nations points to the "hygiene hypothesis". medRxiv. 2020:2020.2007.2031.20165696.doi:10.1101/2020.07.31.20165696

139. Chatterjee B, Karandikar RL, Mande SC. The mortality due to COVID-19 in different nations is associated with the demographic character of nations and the prevalence of autoimmunity. medRxiv. 2020:2020.2007.2031.20165696.doi:10.1101/2020.07.31.20165696

140. Moore M, Gelfeld B, Okunogbe A, Paul C. Identifying Future Disease Hot Spots: Infectious Disease Vulnerability Index. Rand Health Q. 2017;6(3):5-5. https://pubmed.ncbi.nlm.nih.gov/28845357

https://www.ncbi.nlm.nih.gov/pmc/articles/PMC5568150/.

141. Hotez PJ, Kamath A. Neglected tropical diseases in sub-saharan Africa: review of their prevalence, distribution, and disease burden. PLoS Negl Trop Dis. 2009;3(8):e412.doi:10.1371/journal.pntd.0000412

142. Rweyemamu M, Otim-Nape, W., Serwadda, D. Foresight. Infectious Diseases: preparing for the future. Africa. London: Office of Science and Innovation;2006.

143. Elton L, Thomason MJ, Tembo J, et al. Antimicrobial resistance preparedness in subSaharan African countries. Antimicrobial Resistance \& Infection Control. 2020;9(1):145.doi:10.1186/s13756-020-00800-y

144. Eisele TP. Mass drug administration can be a valuable addition to the malaria elimination toolbox. Malaria Journal. 2019;18(1):281.doi:10.1186/s12936-019-2906-8

145. Romani L, Marks M, Sokana O, et al. Feasibility and safety of mass drug coadministration with azithromycin and ivermectin for the control of neglected tropical diseases: a single-arm intervention trial. Lancet Glob Health. 2018;6(10):e1132e1138.doi:10.1016/s2214-109x(18)30397-8

146. Macfarlane CL, Dean L, Thomson R, Garner P. Community drug distributors for mass drug administration in neglected tropical disease programmes: systematic review and analysis of policy documents. Journal of global health. 2019;9(2):020414020414.doi:10.7189/jogh.09.020414

147. Echeverría-Esnal D, Martin-Ontiyuelo C, Navarrete-Rouco ME, et al. Azithromycin in the treatment of COVID-19: a review. Expert Rev Anti Infect Ther. 2021;19(2):147163.doi:10.1080/14787210.2020.1813024

148. Wamae CN. Mass Drug Administration and Worms Experience in Africa: Envisage Repurposing Ivermectin for SARS-COV-2. Am J Trop Med Hyg. 2020;103(1):1011.doi:10.4269/ajtmh.20-0295

149. Hellwig MD, Maia A. A COVID-19 prophylaxis? Lower incidence associated with prophylactic administration of ivermectin. Int J Antimicrob Agents. 2021;57(1):106248.doi:10.1016/j.ijantimicag.2020.106248

150. Caly L, Druce JD, Catton MG, Jans DA, Wagstaff KM. The FDA-approved drug ivermectin inhibits the replication of SARS-CoV-2 in vitro. Antiviral Res. 2020;178:104787-104787.doi:10.1016/j.antiviral.2020.104787

151. COVID-19 Treatment Guidelines: Ivermectin. National Institutes of Health (NIH). https://www.covid19treatmentguidelines.nih.gov/antiviral-therapy/ivermectin/. Updated 02/11/2021. Accessed 04/08/2021. 
152. World malaria report 2019. World Health Organization.

153. Olesen OF, Parker MI. Health research in Africa: getting priorities right. Trop Med Int Health. 2012;17(9):1048-1052.doi:10.1111/j.1365-3156.2012.03027.x

154. Long CA, Zavala F. Immune Responses in Malaria. Cold Spring Harb Perspect Med. 2017;7(8):a025577.doi:10.1101/cshperspect.a025577

155. Artavanis-Tsakonas K, Tongren JE, Riley EM. The war between the malaria parasite and the immune system: immunity, immunoregulation and immunopathology. Clin Exp Immunol. 2003;133(2):145-152.doi:10.1046/j.1365-2249.2003.02174.x

156. Where Malaria Occurs. Centers for Disease Control and Prevention (CDC). https://www.cdc.gov/malaria/about/distribution.html. Updated 04/09/2020. Accessed 04/08/2021.

157. Oyebode O, Kandala NB, Chilton PJ, Lilford RJ. Use of traditional medicine in middleincome countries: a WHO-SAGE study. Health Policy Plan. 2016;31(8):984991.doi:10.1093/heapol/czw022

158. Mahomoodally MF. Traditional medicines in Africa: an appraisal of ten potent african medicinal plants. Evid Based Complement Alternat Med.

2013;2013:617459.doi:10.1155/2013/617459

159. World Health O. WHO global report on traditional and complementary medicine 2019. Geneva: World Health Organization; 2019.

160. Expert panel endorses protocol for COVID-19 herbal medicine clinical trials. World Health Organization. Regional Office for Africa. https:/www.afro.who.int/news/expertpanel-endorses-protocol-covid-19-herbal-medicine-clinical-trials. Updated 09/19/2020. Accessed 04/09/2021.

161. Team AUC-R, Akindele AJ, Agunbiade FO, et al. COVID-19 Pandemic: A Case for Phytomedicines. Nat Prod Commun.

2020;15(8):1934578X20945086.doi:10.1177/1934578X20945086

162. Clinicaltrials.gov.

https:/clinicaltrials.gov/ct2/results?recrs $=\&$ cond $=$ herbal + medicine $\&$ term $=$ COVID$19 \&$ cntry $=\&$ state $=\&$ city $=\&$ dist $=$. Accessed 04/09/2021.

163. Pairo-Castineira E, Clohisey S, Klaric L, et al. Genetic mechanisms of critical illness in COVID-19. Nature. 2021;591(7848):92-98.doi:10.1038/s41586-020-03065-y

164. Zeberg H, Pääbo S. The major genetic risk factor for severe COVID-19 is inherited from Neanderthals. Nature. 2020;587(7835):610-612.doi:10.1038/s41586-020-2818-3

165. Zhao Y, Zhao Z, Wang Y, Zhou Y, Ma Y, Zuo W. Single-Cell RNA Expression Profiling of ACE2, the Receptor of SARS-CoV-2. Am J Respir Crit Care Med. 2020;202(5):756759.doi:10.1164/rccm.202001-0179LE

166. Severe Covid GG, Ellinghaus D, Degenhardt F, et al. Genomewide Association Study of Severe Covid-19 with Respiratory Failure. N Engl J Med. 2020;383(16):15221534.doi:10.1056/NEJMoa2020283

167. Mwangi J. Blood group distribution in an urban population of patient targeted blood donors. East Afr Med J. 1999;76(11):615-618. Published 2000/03/29.

168. Cheng Y, Mohammed S, Okoh A, et al. Association of Blood Type on Clinical Outcomes in Black/African Americans Hospitalized for COVID-19 Infection. Blood. 2020;136(Supplement 1):14-14.doi:10.1182/blood-2020-137556 
169. Rettner R. What's the Rarest Blood Type? Live Science.

https://www.livescience.com/36559-common-blood-type-donation.html. Updated 04/01/2019. Accessed 04/09/2021.

170. Millett GA, Jones AT, Benkeser D, et al. Assessing differential impacts of COVID-19 on black communities. Ann Epidemiol. 2020;47:37-44.doi:10.1016/j.annepidem.2020.05.003

171. Tishkoff SA, Reed FA, Friedlaender FR, et al. The genetic structure and history of Africans and African Americans. Science. 2009;324(5930):10351044.doi:10.1126/science. 1172257

172. Bryc K, Auton A, Nelson MR, et al. Genome-wide patterns of population structure and admixture in West Africans and African Americans. Proceedings of the National Academy of Sciences. 2010;107(2):786-791.doi:10.1073/pnas.0909559107

173. Cooper R, Rotimi C, Ataman S, et al. The prevalence of hypertension in seven populations of west African origin. Am J Public Health. 1997;87(2):160168.doi:10.2105/ajph.87.2.160

174. Carnethon MR, Pu J, Howard G, et al. Cardiovascular Health in African Americans: A Scientific Statement From the American Heart Association. Circulation. 2017;136(21):e393-e423.doi:10.1161/cir.0000000000000534

175. Income Gini coefficient. United Nations Development Programme (UNDP). Human Development Reports Web site. http://hdr.undp.org/en/content/income-gini-coefficient. Accessed 04/09/2021.

176. Yaya S, Yeboah $\mathrm{H}$, Charles $\mathrm{CH}$, Otu A, Labonte R. Ethnic and racial disparities in COVID-19-related deaths: counting the trees, hiding the forest. BMJ Glob Health. 2020;5(6).doi:10.1136/bmjgh-2020-002913

177. Sze S, Pan D, Nevill CR, et al. Ethnicity and clinical outcomes in COVID-19: A systematic review and meta-analysis. EClinicalMedicine.

2020;29:100630.doi:10.1016/j.eclinm.2020.100630

178. Andrews GR. Racial Inequality in Brazil and the United States: A Statistical Comparison. Journal of Social History. 1992;26(2):229-263. http://www.jstor.org/stable/3788420. Accessed 2021/04/04/.

179. Hamilton CV, Initiative CHR, Huntley L, Alexander N, Guimardes ASA, James W. Beyond Racism: Race and Inequality in Brazil, South Africa, and the United States. Lynne Rienner Publishers; 2001.

180. Finch WH, Hernández Finch ME. Poverty and Covid-19: Rates of Incidence and Deaths in the United States During the First 10 Weeks of the Pandemic. Frontiers in Sociology. 2020;5(47).doi:10.3389/fsoc.2020.00047

181. Viens AM, Eyawo O. COVID-19: the rude awakening for the political elite in low- and middle-income countries. BMJ Global Health. 2020;5(5):e002807.doi:10.1136/bmjgh2020-002807

182. Nwosu CO, Oyenubi A. Income-related health inequalities associated with the coronavirus pandemic in South Africa: A decomposition analysis. International Journal for Equity in Health. 2021;20(1):21.doi:10.1186/s12939-020-01361-7

183. Musa HH, Musa TH, Musa IH, Musa IH, Ranciaro A, Campbell MC. Addressing Africa's pandemic puzzle: Perspectives on COVID-19 transmission and mortality in sub-Saharan Africa. Int J Infect Dis. 2021;102:483-488.doi:10.1016/j.ijid.2020.09.1456

184. Kuehn BM. Africa Succeeded Against COVID-19's First Wave, but the Second Wave Brings New Challenges. JAMA. 2021;325(4):327-328.doi:10.1001/jama.2020.24288 
185. Muiruri P. Covid third wave may overrun Africa's healthcare, warns WHO. The Guardian. 03/26/2021.

186. Collaborators GHAaQ. Measuring performance on the Healthcare Access and Quality Index for 195 countries and territories and selected subnational locations: a systematic analysis from the Global Burden of Disease Study 2016. Lancet. 2018;391(10136):22362271.doi:10.1016/s0140-6736(18)30994-2

187. Dente MG, Resti CV, Declich S, Putoto G. The Reported Few Cases and Deaths of Covid-19 Epidemic in Africa Are Still Data Too Questionable to Reassure About the Future of This Continent. Front Public Health. 2021;9:613484.doi:10.3389/fpubh.2021.613484

188. Headey D, Heidkamp R, Osendarp S, et al. Impacts of COVID-19 on childhood malnutrition and nutrition-related mortality. Lancet. 2020;396(10250):519521.doi:10.1016/s0140-6736(20)31647-0

189. Jewell BL, Mudimu E, Stover J, et al. Potential effects of disruption to HIV programmes in sub-Saharan Africa caused by COVID-19: results from multiple mathematical models. Lancet HIV. 2020;7(9):e629-e640.doi:10.1016/s2352-3018(20)30211-3

190. 2020 Goalkeepers Report. COVID-19 A Global Perspective. https://www.gatesfoundation.org/goalkeepers/report/2020-report/\#GlobalPerspective. Accessed 4/14/2021.

191. More than 117 million children at risk of missing out on measles vaccines, as COVID-19 surges. Immunization, Vaccines and Biologicals Web site.

https://www.who.int/immunization/diseases/measles/statement_missing_measles_vaccine s_covid-19/en/. Updated 4/14/2020. Accessed 4/14/2021.

192. Coronavirus disease (COVID-19): Herd immunity, lockdowns and COVID-19. World Health Organization. https://www.who.int/news-room/q-a-detail/herd-immunitylockdowns-and-covid19?gclid=CjwKCAjwr_uCBhAFEiwAX8YJgVKPC4VjiRuciYR8yxynYd_hzAOgVyRLNIŪNTwEgnwPofTqdvR1wRoCxOgQAvD_BwE. Updated 12/31/2020. Accessed 04/09/2021.

193. HIV/AIDS. World Health Organization. Regional Office for Africa. https://www.afro.who.int/health-topics/hivaids. Accessed 04/09/2021.

194. Sankoh O, Dickson KE, Faniran S, et al. Births and deaths must be registered in Africa. Lancet Glob Health. 2020;8(1):e33-e34.doi:10.1016/s2214-109x(19)30442-5

195. Bedford J, Farrar J, Ihekweazu C, Kang G, Koopmans M, Nkengasong J. A new twentyfirst century science for effective epidemic response. Nature. 2019;575(7781):130136.doi:10.1038/s41586-019-1717-y 